University of Wollongong

Research Online

Australian Institute for Innovative Materials -

Papers

Australian Institute for Innovative Materials

$1-1-2015$

Conductive surfaces with dynamic switching in response to temperature and salt

\author{
Alissa Hackett \\ University of Auckland \\ Jenny Malmström \\ University of Auckland \\ Paul J. Molino \\ University of Wollongong, pmolino@uow.edu.au \\ Julien Gautrot \\ Queen Mary University of London \\ Hongrui Zhang \\ University of Wollongong, hz215@uowmail.edu.au
}

See next page for additional authors

Follow this and additional works at: https://ro.uow.edu.au/aiimpapers

Part of the Engineering Commons, and the Physical Sciences and Mathematics Commons

Research Online is the open access institutional repository for the University of Wollongong. For further information contact the UOW Library: research-pubs@uow.edu.au 


\title{
Conductive surfaces with dynamic switching in response to temperature and salt
}

\begin{abstract}
This work demonstrates polymer brushes grafted from conductive polymer films which display dynamic surface switching dependent on salt, temperature and electrode potential. The electroactivity presented by the conductive polymer and the responsiveness of the grafted brushes leads to an interface with multiple control parameters. Here, we demonstrate this concept by grafting of uncharged brushes of poly(ethylene glycol)methyl ether methacrylates from conducting polymer poly(3,4-ethylenedioxythiophene) (PEDOT), and observe a temperature- and salt-induced switch of brush conformation, and their effect on the electrochemistry of the material. The switching conditions can be tailored by copolymerizing monomers with different numbers of ethylene glycol units. In addition, these surfaces exhibit antifouling properties, leading to potential applications such as electrically-addressable biointerfaces.
\end{abstract}

\section{Keywords}

salt, temperature, response, switching, dynamic, surfaces, conductive

Disciplines

Engineering | Physical Sciences and Mathematics

\section{Publication Details}

Hackett, A. J., Malmström, J., Molino, P. J., Gautrot, J. E., Zhang, H., Higgins, M. J., Wallace, G. G., Williams, D. E. \& Travas-Sejdic, J. (2015). Conductive surfaces with dynamic switching in response to temperature and salt. Journal of Materials Chemistry B, 3 (48), 9285-9294.

\section{Authors}

Alissa Hackett, Jenny Malmström, Paul J. Molino, Julien Gautrot, Hongrui Zhang, Michael J. Higgins, Gordon G. Wallace, David E. Williams, and Jadranka Travas-Sejdic 


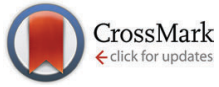

Cite this: J. Mater. Chem. B, 2015, 3, 9285

Received 13th October 2015, Accepted 12th November 2015

DOI: $10.1039 / c 5 t b 02125 a$

www.rsc.org/MaterialsB

\section{Conductive surfaces with dynamic switching in response to temperature and salt $\dagger$}

\author{
Alissa J. Hackett, ${ }^{a b}$ Jenny Malmström, ${ }^{\text {ab }}$ Paul J. Molino, ${ }^{c}$ Julien E. Gautrot, ${ }^{d}$ \\ Hongrui Zhang, ${ }^{c}$ Michael J. Higgins, ${ }^{c}$ Gordon G. Wallace, ${ }^{c}$ David E. Williams ${ }^{\mathrm{ab}}$ and \\ Jadranka Travas-Sejdic*ab
}

\begin{abstract}
This work demonstrates polymer brushes grafted from conductive polymer films which display dynamic surface switching dependent on salt, temperature and electrode potential. The electroactivity presented by the conductive polymer and the responsiveness of the grafted brushes leads to an interface with multiple control parameters. Here, we demonstrate this concept by grafting of uncharged brushes of poly(ethylene glycol)methyl ether methacrylates from conducting polymer poly(3,4-ethylenedioxythiophene) (PEDOT), and observe a temperature- and salt-induced switch of brush conformation, and their effect on the electrochemistry of the material. The switching conditions can be tailored by copolymerizing monomers with different numbers of ethylene glycol units. In addition, these surfaces exhibit antifouling properties, leading to potential applications such as electrically-addressable biointerfaces.
\end{abstract}

\section{Introduction}

Materials with stimuli-responsive properties have gained considerable interest in recent years, particularly in the area of biomaterials. The ability to control surface properties with an external stimulus lends itself to many applications, including biomedical devices and tissue engineering scaffolds, as well as chromatographic substrates, self-cleaning coatings, microfluidic devices, and chemical or biological sensors. ${ }^{1-3}$ Recent advances in surface functionalization has led to the development of materials that respond to multiple stimuli, such as temperature, $\mathrm{pH}$ and salt, allowing them to be better tailored towards specific applications. ${ }^{4-6}$ Electrically conducting polymers (CPs) are $\pi$-conjugated systems that can be reversibly transformed from insulating to electrically conducting states by a redox process (referred to as doping/dedoping). ${ }^{7,8}$ As a result, CPs are utilized in a range of applications requiring electrochemical control, including chemical, gas and biosensors,

\footnotetext{
${ }^{a}$ Polymer Electronics Research Centre, School of Chemical Sciences,

University of Auckland, New Zealand. E-mail: j.malmstrom@auckland.ac.nz, j.travas-sejdic@auckland.ac.nz

${ }^{b}$ MacDiarmid Institute for Advanced Materials and Nanotechnology, New Zealand ${ }^{c}$ ARC Centre of Excellence for Electromaterials Science, Intelligent Polymer Research Institute, University of Wollongong, NSW, Australia

${ }^{d}$ School of Engineering and Materials Science, Queen Mary University of London, UK $\dagger$ Electronic supplementary information (ESI) available: Additional details of ellipsometry, QCM-D and EIS methodology, electropolymerization CVs of PEDOT- $c$-PBrEDOT, UV-vis turbidity measurements, full FTIR spectra, characterization CVs at 5 and $50{ }^{\circ} \mathrm{C}$, an example of raw electrochemical impedance spectra and modelled parameters, and additional QCM-D measurements are given. See DOI: $10.1039 / \mathrm{c} 5$ tb02125a
}

drug delivery systems, actuators, micro- and optoelectronics, and photonics. ${ }^{9,10}$ More recently, CPs have been exploited as materials in biomedical engineering and as interfaces to improve compatibility between electronic biomedical devices and living tissues. ${ }^{7,11-13}$ However, their use is limited due to their restricted surface chemistry, poor processability and issues with surface fouling. ${ }^{10,14}$ To address these issues, techniques such as ATRP (atom transfer radical polymerization) and RAFT (reversible addition-fragmentation chain transfer polymerization) have been used to graft polymeric brushes from CP macroinitiators. Typically, the aim has been to achieve soluble $\mathrm{CPs}^{15}$ or $\mathrm{CPs}$ with altered optical properties in solution. ${ }^{16}$ More recently, grafting from CP films has been used as a route to producing functional surfaces that retain the electrochemical activity of the CP backbone. Grande et al. reported the first study on grafting of polymethylmethacrylate and polystyrene brushes from an electrochemically produced polyterthiophene backbone. ${ }^{17}$ Since then, grafted brushes have been used to improve $\mathrm{CP}$ hydrophilicity, ${ }^{18}$ modulate electrochemical behavior of CP-based biosensors towards analytes of interest, ${ }^{19}$ and recently to introduce antifouling behavior. ${ }^{20}$

An additional layer of control over the surface properties can be added through the use of stimuli-responsive polymer brushes. Depending on the desired stimuli, surface properties can be modulated either via the electrochemistry of the $\mathrm{CP}$ backbone, or independently through changes in the environment. We have previously reported electrochemical switching of a CP- $g$-polyacrylic acid, ${ }^{21}$ a CP- $g$-(polystyrene- $b$-polyacrylic acid) ${ }^{22}$ and a CP-g-poly(zwitterion), ${ }^{23,24}$ where switching was 
induced by phenomena such as surface wetting, electrostatic interactions and the CP's doping/dedoping process which changes the local ion concentration.

A particularly interesting class of polymer brushes are the dually-responsive temperature- and salt-sensitive polymers, such as poly( $N$-isopropylacrylamide) (PNIPAM), and polymers synthesized from ethylene glycol macromonomer derivatives such as di- and poly(ethylene glycol)methyl ether methacrylates (DEGMMA and PEGMMA respectively). These types of materials have revolutionized the field of cell sheet engineering, by creating surfaces that allow cell growth at $37{ }^{\circ} \mathrm{C}$, but become cell-rejecting at room temperature, allowing cell harvesting without the use of enzymes that may disrupt the cell sheets. ${ }^{3,25-27}$ The temperature at which the transition occurs can be raised or lowered respectively by the presence of chaotropic and kosmotropic salts in solution. ${ }^{28,29}$ In the case of P(PEGMMA), the transition temperature may also be tailored through the number of ethylene glycol units in the macromonomer. ${ }^{30} \mathrm{P}$ (PEGMMA)based materials have been well studied in solution ${ }^{28-31}$ and as brushes grown from surface initiation sites presented from thiol $^{25}$ or silane monolayers. ${ }^{32}$

In this study, we grafted PEGMMA-type brushes from a conductive polymer surface, thereby creating functional conducting interfaces with tunable surface chemistry. The functional CP surfaces thus created are electrochemically active and stable over a wider potential range than those grafted from thiol monolayers on gold. ${ }^{33}$

Specifically, the grafting of the salt- and temperatureresponsive co-polymers of $\mathrm{P}$ (PEGMMA-co-DEGMMA) from the conductive polymer poly(3,4-ethylenedioxythiophene (PEDOT) is demonstrated. Switching of the brushes in response to various salts concentrations and temperature is studied by quartz crystal microbalance with dissipation (QCM-D), ellipsometry and atomic force microscopy (AFM) measurements. The presence of the conductive polymer allows us to use electrochemical methods, such as cyclic voltammetry and electrochemical impedance spectroscopy (EIS) to probe the brushes, leading to new insights into the brush behavior. These techniques collectively reveal the subtleties of the transition, which is critical for tailoring the PEDOT films for relevant applications, and have not been reported previously. Additionally, we demonstrated a strong antifouling effect of the grafted brushes, as an example of use of these conductive surfaces as possible biointerfaces. The chemistry and analysis presented here provides a framework for the design of CP biointerfaces with tailored, stimuli-responsive protein and cell interactions.

\section{Materials and methods}

\subsection{Materials}

All chemicals were purchased from Sigma-Aldrich, with the exception of ascorbic acid (BDH Chemicals), sodium chloride (ECP Chemicals) and sodium sulfate (Scharlau). Di(ethylene glycol)methyl ether methacrylate (DEGMMA), poly(ethylene glycol)methyl ether methacrylate $M_{\mathrm{W}} \sim 500$ (PEGMMA-500) and 3,4-ethylenedioxythiophene (EDOT) were not purified before use. Milli-Q water (18.2 $\mathrm{M} \Omega \mathrm{cm}$ ) was used in all aqueous solutions.

\subsection{Synthesis of (3,4-ethylenedioxythiophene)methyl 2- bromopropanoate (BrEDOT)}

(3,4-Ethylenedioxythiophene)methyl 2-bromopropanoate (BrEDOT) was synthesized from hydroxymethyl EDOT according to a previously-reported method. ${ }^{21}$ The crude product was purified using a neutral alumina column ( $7: 1$ hexane/ethyl acetate) to give BrEDOT as a yellow oil (484 $\mathrm{mg}, 54.3 \%$ yield).

\subsection{Electropolymerization of P(EDOT-co-BrEDOT)}

All electropolymerization was carried out using a three electrode cell setup, with an Au-coated substrate as the working electrode, Pt mesh counter electrode, and $\mathrm{Ag} / \mathrm{AgCl}(3 \mathrm{M} \mathrm{KCl})$ reference electrode $(+0.210 \mathrm{~V} v s$. SHE). Gold-coated glass electrodes ( $\mathrm{Ti}$ adhesion layer) were cleaned electrochemically by cycling the potential between -0.5 to $1.6 \mathrm{~V}$ in $0.5 \mathrm{M} \mathrm{H}_{2} \mathrm{SO}_{4}$ for 10 cycles, until the cyclic voltammograms stabilized. QCM-D crystals (Q-Sense, Sweden) were cleaned in piranha solution for 3 minutes. All substrates were rinsed thoroughly with Milli-Q and dried under nitrogen. Films were polymerized by cyclic voltammetry in two layers. First, an adhesion layer of PEDOT was deposited from a solution containing $0.02 \mathrm{M}$ EDOT and $0.1 \mathrm{M}$ sodium $p$-toluenesulfonate in $3: 1$ acetonitrile/water $\left(-0.3\right.$ to $1.4 \mathrm{~V}, 100 \mathrm{mV} \mathrm{s}^{-1}, 1$ cycle). After rinsing with acetonitrile, a second layer of PBrEDOT was deposited on top from $0.02 \mathrm{M} \mathrm{BrEDOT} / 0.1 \mathrm{M} \mathrm{LiClO}_{4}$ in acetonitrile ( -0.3 to $1.4 \mathrm{~V}$, $100 \mathrm{mV} \mathrm{s}^{-1}, 1$ cycle). Films were then rinsed with acetonitrile and water and dried with nitrogen. Cyclic voltammograms are given in the ESI $\dagger$ (Fig. S1).

\subsection{SI-AGET ATRP of P(PEGMMA-co-DEGMMA) brushes}

Surface-initiated grafting of brushes was carried out using AGET (activators generated by electron transfer) ATRP. Brushes consisted of either PDEGMMA homopolymers, or P(PEGMMA500-co-DEGMMA) copolymers in a 1:5 or 1:9 monomer ratio.

The PBrEDOT substrate was added to a solution of $\mathrm{CuCl}_{2}$ (3.3 $\mathrm{mg}, 25 \mu \mathrm{mol})$ and PMDTA $(5.22 \mu \mathrm{L}, 25 \mu \mathrm{mol})$ in ethanol (4.7 $\mathrm{mL})$. Monomer was added, totaling $7.2 \mathrm{mmol}$, and the flask was sealed and purged with nitrogen for $1 \mathrm{~h}$. Ascorbic acid (1.54 mg, $8.75 \mathrm{mmol}$ ), dissolved in $0.5 \mathrm{~mL}$ Milli-Q, was added dropwise. The reaction was left under nitrogen for $18 \mathrm{~h}$ at $40{ }^{\circ} \mathrm{C}$ before being stopped by exposing to air. The films were washed with ethanol, Milli-Q and $50 \mathrm{mM}$ EDTA. Brushes were also grafted directly from silicon substrates for ellipsometry measurements.

Equivalent free polymer chains for turbidity measurements were produced by replacing the substrates with methyl 2-bromopropionate $(16.06 \mu \mathrm{L}, 144 \mu \mathrm{mol})$ as an initiator, and purified by dialysis in water.

\subsection{Characterization}

2.5.1 Turbidity measurements of free polymers. Turbidity measurements of free polymers (analogous to the grafted brushes) 
were measured with a Shimadzu UV-1700 spectrophotometer with S-1700 temperature control unit. Solutions containing $2 \mathrm{~g} \mathrm{~L}^{-1}$ polymer and $0-1 \mathrm{M}$ of salt $\left(\mathrm{NaClO}_{4}, \mathrm{NaCl}, \mathrm{Na}_{2} \mathrm{SO}_{4}\right)$ were heated from $5-95{ }^{\circ} \mathrm{C}$ at a rate of $1{ }^{\circ} \mathrm{C} \mathrm{min}^{-1}$. Absorbance was measured at $550 \mathrm{~nm}$ and converted to transmittance. The cloud point was calculated as the temperature at which transmittance drops to $50 \%$ of its original value.

2.5.2 Water contact angle measurements. The presence of grafted brushes was confirmed by measuring changes in surface hydrophobicity using a CAM 100 contact angle meter (KSV Instruments). Two samples were made for each brushcomposition and four drops were recorded on each sample, giving a total of eight measurements per composition.

2.5.3 FTIR. FTIR spectra were recorded using a Nicolet 8700 Thermo Electron FTIR spectrometer fitted with a Smart Orbit diamond ATR accessory. Spectra were recorded in ATR mode with a resolution of $4 \mathrm{~cm}^{-1}$, and averaged over three spots per sample. Data processing was carried out using OMNIC spectroscopic software.

2.5.4 Ellipsometry. Ellipsometry measurements were carried out with an $\alpha-\mathrm{SE}^{\circledR}$ spectroscopic ellipsometer from J. A. Woollam Co. All measurements were carried out in triplicate, at three different locations on the sample, at room temperature $\left(23{ }^{\circ} \mathrm{C}\right)$ and at a fixed incident angle of $70^{\circ}$. All data was fitted between 400 and $900 \mathrm{~nm}$. Details of the data modelling may be found in the ESI. $\dagger$ For measurements in aqueous salt solutions, a flow chamber $(500 \mu \mathrm{L}, \mathrm{J}$. A. Woollam Co.) fitted with quartz windows normal to the laser beam path was mounted on top of the sample. This allowed the in situ measurement of swollen coatings in salt solutions. The small volume of the chamber allowed us to flow through salt solutions sequentially with increasing salt concentrations, without drying of the sample.

2.5.5 AFM. Two kinds of films were prepared for AFM measurements: an ungrafted PBrEDOT control and a PBrEDOT$g$-P(PEGMMA-co-DEGMMA, $1: 9)$ film. The surface morphology of the polymer films were imaged using a JPK Biowizard II Atomic Force Microscope (JPK Instruments, Germany). Images were taken with Bruker DNP-S10 cantilevers (spring constant $\sim 0.12 \mathrm{~N} \mathrm{~m}^{-1}$ ) using intermittent contact mode in fluid. Scans $(5 \mu \mathrm{m} \times 5 \mu \mathrm{m})$ were obtained using tip velocities ranging from $2.5 \mu \mathrm{m} \mathrm{s}^{-1}$ to $20 \mu \mathrm{m} \mathrm{s}^{-1}$; the PBrEDOT- $g$-P(PEGMMA-co-DEGMMA) film was scanned under the lowest amplitude set point and scan rate due to its softness. The images were analyzed using JPK Data Processing software.

2.5.6 Quartz crystal microbalance with dissipation (QCM-D). QCM-D measurements were carried out on a Q-Sense E4 quartz crystal microbalance with dissipation with four flow cells for simultaneous measurements, and were recorded using Q-Soft software. Films were polymerized directly on to gold-coated QCM-D crystals. Baseline frequency and dissipation were measured in Milli-Q water. Measurements at varying salt concentrations (10-1000 mM) were carried out at $22{ }^{\circ} \mathrm{C}$ in $\mathrm{NaClO}_{4}$, $\mathrm{NaCl}$ and $\mathrm{Na}_{2} \mathrm{SO}_{4}$. Temperature measurements were also carried out in $100 \mathrm{mM} \mathrm{NaCl}$ and $\mathrm{Na}_{2} \mathrm{SO}_{4}$ solutions, with the temperature stepped from 22 to $40{ }^{\circ} \mathrm{C}$ at a rate of $1{ }^{\circ} \mathrm{C} / 20 \mathrm{~min}$. The antifouling behavior of the films was tested by adding a solution of $20 \%$ fetal bovine serum (FBS) in HAMS F10 media, and recording the frequency and dissipation change associated with the increase in mass caused by protein adsorption.

2.5.7 Electrochemistry. Cyclic voltammetry (CV) and electrochemical impedance spectroscopy (EIS) were carried out on a Bio-Logic SP-300 potentiostat using a three electrode setup: the polymer-modified gold substrate as a working electrode, Pt mesh counter electrode and $\mathrm{Ag} / \mathrm{AgCl}(3 \mathrm{M} \mathrm{KCl})$ reference electrode $(+0.210 \mathrm{~V}$ vs. SHE). The temperature was controlled by a Shimadzu S-1700 thermoelectric UV-vis cell holder. Solutions containing $0.1 \mathrm{M} \mathrm{NaClO}_{4}, \mathrm{NaCl}$ or $\mathrm{Na}_{2} \mathrm{SO}_{4}$ were used as electrolytes. Cyclic voltammetry was carried out by potential cycling between -0.5 to $1.0 \mathrm{~V}$ at $100 \mathrm{mV} \mathrm{s}^{-1}$ at 5,30 and $50{ }^{\circ} \mathrm{C}$.

Non-faradaic EIS was carried out in $0.1 \mathrm{M}$ electrolyte (without a redox mediator $)^{23,24}$ at a bias of $0.3 \mathrm{~V}$ with $5 \mathrm{mV}$ amplitude, with the frequency ranging from $10 \mathrm{kHz}$ to $0.1 \mathrm{mHz}$ (12 points per decade). Impedance was measured every $1{ }^{\circ} \mathrm{C}$ from $5-50{ }^{\circ} \mathrm{C}$. Spectra were analyzed with Bio-Logic EC-Lab software using a modified Bisquert model for a transmission line, as shown in Fig. S2 (ESI $\dagger){ }^{23}$ An explanation of the modelling parameters is given in the ESI. $\dagger$

To confirm that observed trends in the calculated values were reflected in the raw data and not a result of interdependent co-variables while modelling, the gradient of the low frequency region $(<1 \mathrm{~Hz})$ was also calculated. This region probes slow processes such as ion diffusion into the $\mathrm{CP}$ layer, which may be affected by the presence of grafted brushes.

\section{Results and discussion}

\subsection{Synthesis of PBrEDOT-g-P(PEGMMA-co-DEGMMA)}

In order to graft P(PEGMMA) and P(DEGMMA) brushes from conductive polymer layers, (3,4-ethylenedioxythiophene)methyl 2-bromopropanoate (BrEDOT) was used as a polymeric macroinitiator, as previously reported by us. ${ }^{21}$ Two thin layers of conducting polymer were electrochemically deposited on to gold substrates. The first layer consisted of PEDOT doped with sodium $p$-toluenesulfonate to provide good adhesion to the substrate. A second layer of PBrEDOT (doped with $\mathrm{LiClO}_{4}$, due to the improved polymerization seen with this dopant) was subsequently added to provide ATRP initiating sites for grafting. The produced PBrEDOT films were very adhesive and able to withstand the standard tape test. These PBrEDOT films were subsequently 'grafted from' with PEGMMA/DEGMMA by means of SI-AGET ATRP. Fig. 1 shows the general scheme of sample preparation.

The brushes in this study were grafted using PEGMMA-500 and DEGMMA macromonomers due to their thermoresponsiveness, leading to a transition between swollen (hydrated) and collapsed (dehydrated) states. ${ }^{28,30}$ The transition temperature increases with increasing number of ethylene glycol units present $^{30,31}$ ( $\sim 9$ for PEGMMA-500, 2 for DEGMMA); thus we can tailor the transition temperature by copolymerizing these two monomers in different ratios, as shown by turbidity measurements of free polymers in solution (Fig. S3b, ESI $\dagger$ ). 


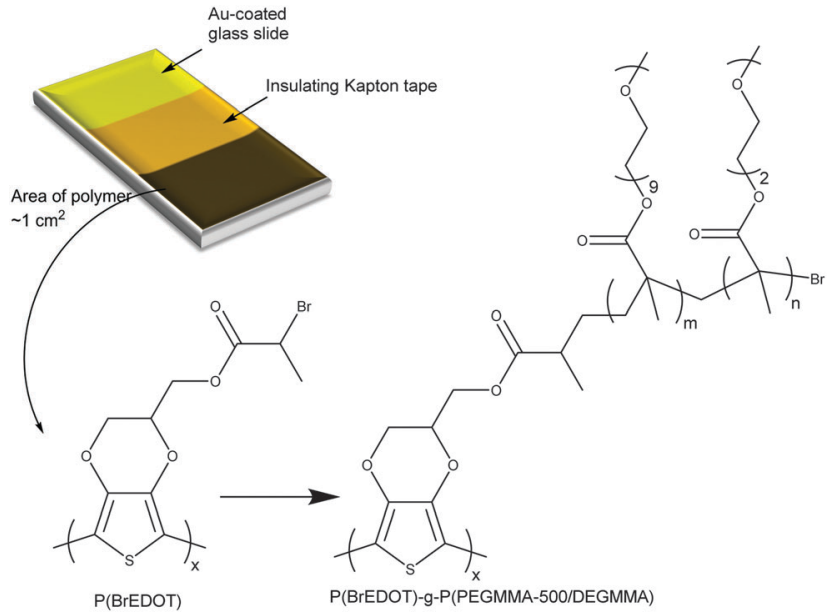

Fig. 1 General reaction scheme showing polymerization of $\mathrm{P}(\mathrm{BrEDOT})$ and subsequent grafting of P(PEGMMA-CO-DEGMMA) brushes via SI-AGET ATRP.

In this work, we investigated brushes consisting of P(DEGMMA) homopolymers and P(PEGMMA-co-DEGMMA) copolymers with monomer ratios of $1: 9$ and $1: 5$ respectively. Fig. S4 (ESI $\dagger$ ) demonstrates how the transition temperature can be raised by the addition of $\mathrm{NaClO}_{4}$ ('salting in'), or lowered by the addition of $\mathrm{NaCl}$ and $\mathrm{Na}_{2} \mathrm{SO}_{4}$ ('salting out'), corresponding to the Hofmeister series of anions. ${ }^{29}$

Fig. S5 in the ESI $\dagger$ shows FT-IR spectra of films grafted with P(PEGMMA-co-DEGMMA, 1:5) for various times, as well as the ungrafted control, and verifies successful grafting. The FT-IR spectra were also used to follow the growth of the brushes and indicated that the polymerization halts after 2 hours, possibly due to chain termination and consumption of the ascorbic acid (Fig. S5c, ESI $\dagger){ }^{34}$

Water contact angle measurements demonstrate that the grafting of $\mathrm{P}$ (PEGMMA-co-DEGMMA) makes the films less hydrophilic with contact angles of $48 \pm 2^{\circ}$ for PBrEDOT- $g$ P(PEGMMA-co-DEGMMA, $1: 5)$, as compared to ungrafted PBrEDOT which presented a contact angle of $28 \pm 3^{\circ}$. These contact angles were recorded at room temperature $\left(c a .23{ }^{\circ} \mathrm{C}\right)$, and the samples were dried with a stream of nitrogen prior to the measurement. The brushes were therefore assumed to be dehydrated, and thus would be expected to be more hydrophilic in the swollen state.

\subsection{Brush thickness in response to salt concentration - ellipsometry and AFM}

Spectroscopic ellipsometry is a suitable methodology to study the thickness of the brush layer and the change in the thickness upon exposure to salt solutions. Very thin conductive polymer layers (40-60 nm when dry) were used for ellipsometry measurements to reduce light absorption from PEDOT, which is optically active in part of the spectrum probed by ellipsometry. Brushes grafted directly from silicon wafers, without the conductive polymer layer, were also investigated to aid with modelling and interpretation (see Fig. S6, ESI $\dagger$ ). The modelling procedure is
Table 1 Dry thicknesses of brushes grafted from both Si and PBrEDOT substrates, obtained from ellipsometry measurements

\begin{tabular}{llc}
\hline & \multicolumn{2}{l}{ Dry thickness of brushes $(\mathrm{nm})$} \\
\cline { 2 - 3 } Brush composition & Si substrate & PBrEDOT substrate \\
\hline PDEGMMA & $80.6 \pm 0.1$ & $131 \pm 6.0$ \\
P(PEGMMA-co-DEGMMA, 1:9) & $86.6 \pm 0.9$ & $92 \pm 2.0$ \\
P(PEGMMA-co-DEGMMA, 1:5) & $98.0 \pm 2.0$ & $137 \pm 5.0$
\end{tabular}

detailed in the ESI. $\nmid$ The calculated dry thicknesses of the PDEGMMA, P(PEGMMA-co-DEGMMA, 1:9) and P(PEGMMA-coDEGMMA, 1:5) brushes from each substrate are collated in Table 1, and were found to be in the range from 80-140 $\mathrm{nm}$. Brushes were seen to increase in thickness slightly as the amount of PEGMMA increased. Brushes were thicker when grown from the PBrEDOT substrates compared to the corresponding silicon substrates.

Fig. 2a shows the percentage increase of brush thickness (swelling), compared to the dry thickness, when exposed to increasing concentration of $\mathrm{NaCl}$ salt solutions at room temperature. The brushes grafted from the conductive polymer layer show collapse starting at $0.4 \mathrm{M}$ salt concentration. This is expected for the PDEGMMA brushes, as the cloud point transition for the corresponding free polymer in $\mathrm{NaCl}$ solution occurs at room temperature at $\sim 0.35 \mathrm{M} \mathrm{NaCl}$ (Fig. S4a, ESI $\dagger$ ). However, this concentration is lower than expected for the copolymer compositions (Fig. S4c and d, ESI $\dagger$ ). This shift in transition temperatures in brushes compared to free polymers has been observed previously, ${ }^{35}$ and was attributed to a bulk brush collapse associated with the high grafting density. The swelling is moderate for the PDEGMMA and P(PEGMMA-co-DEGMMA, $1: 5)$ brushes, but is increased for the PBrEDOT- $g$-P(PEGMMAco-DEGMMA, 1:9) brushes compared to the corresponding brushes grafted from $\mathrm{Si}$; this behavior may arise from some level of swelling of the underlying PEDOT with the associated change in optical constants, due to some interpenetration of the brush with the PEDOT layer. This observation was supported by the AFM data discussed below.

Atomic force microscopy (AFM) imaging of the ungrafted PBrEDOT and grafted P(PEGMMA-co-DEGMMA, 1:9) samples was carried out in water and high salt conditions. To facilitate brush collapse, $\mathrm{Na}_{2} \mathrm{SO}_{4}$ was used in the place of $\mathrm{NaCl}$, due to its stronger salting out effect. ${ }^{29}$ First, the ungrafted PBrEDOT film was imaged in water (Fig. 2b), followed by exposure to $1 \mathrm{M} \mathrm{Na}_{2} \mathrm{SO}_{4}$ without drying the film (Fig. 2c). Both of these images display nodular morphology typical of PEDOT films. ${ }^{36}$ RMS roughnesses were $28.5 \mathrm{~nm}$ for the ungrafted PBrEDOT and $19.5 \mathrm{~nm}$ for the grafted brushes. Imaging of PBrEDOT- $g$-P(PEGMMA-co-DEGMMA, $1: 9)$ in water showed that the expected nodule structures of the $\mathrm{CP}$ were present, although the structures appeared larger due to the presence of the brush layer (Fig. 2d). These surfaces were also qualitatively observed to be softer, as indicated by damage to the polymer (i.e. smearing effects in the image) caused by lateral forces of the AFM tip during scanning. Thus, lower imaging forces and scan rates were required to obtain images of the PBrEDOT- $g$-P(PEGMMA-co-DEGMMA, $1: 9$ ). There appears 

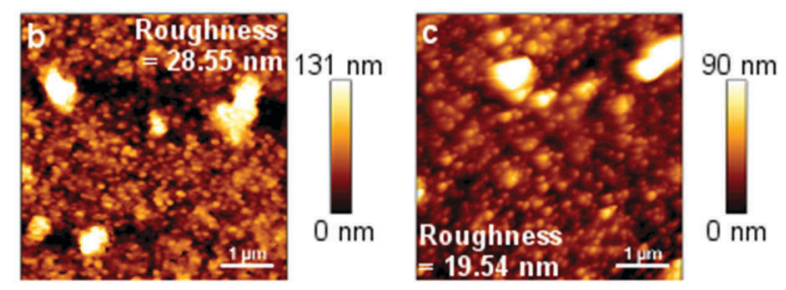

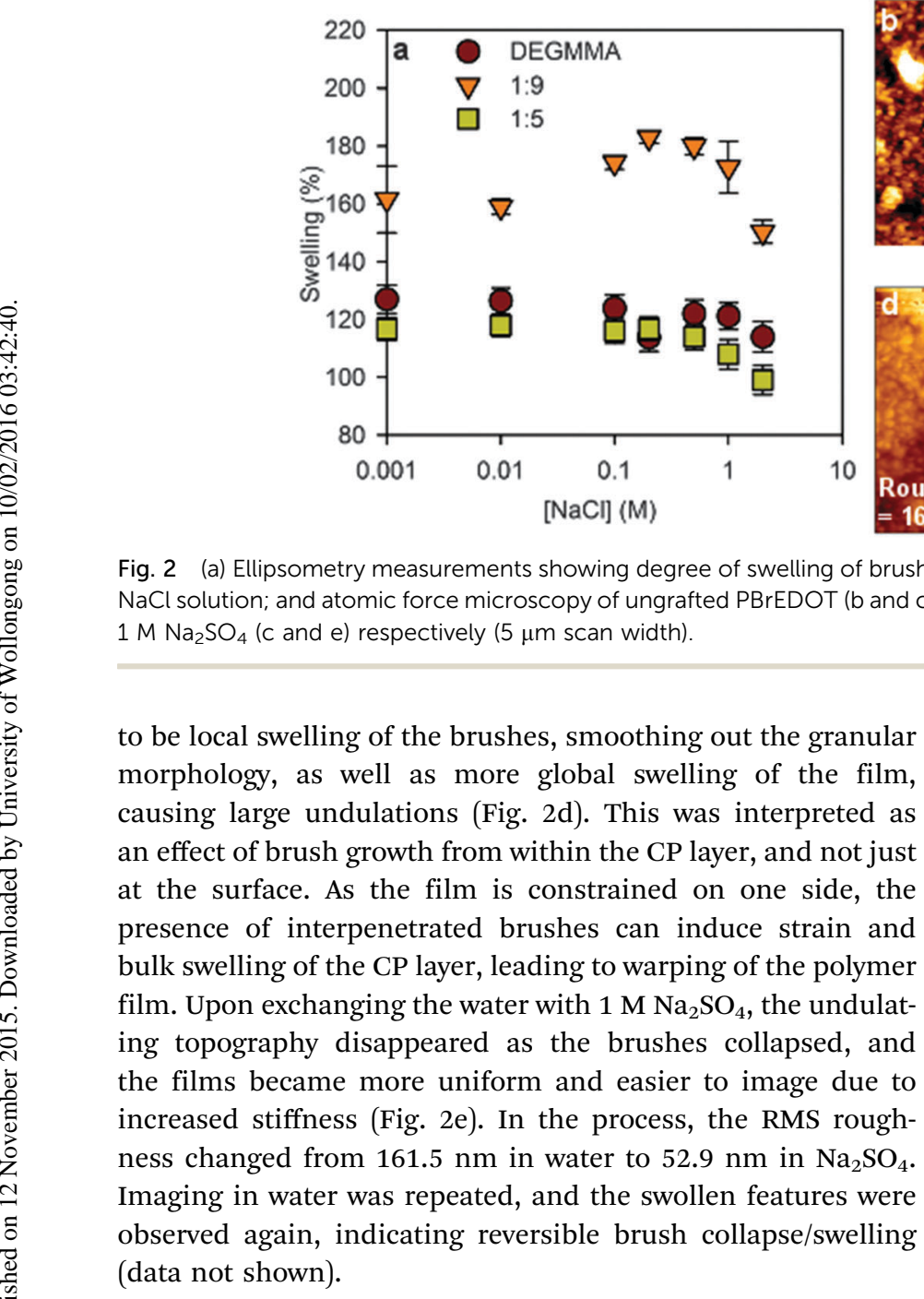

\subsection{Salt- and temperature-responsiveness measured by QCM-D}

To observe the changes in hydration of the brush layers upon exposure to different salt solutions in more detail, quartz crystal microbalance with dissipation (QCM-D) was employed. As the brushes swell and collapse, the hydrated mass and the viscoelastic properties of the layer are expected to change, resulting in an observable response in the frequency and dissipation. Conducting polymer films were prepared on goldcoated QCM-D crystals and grafted with P(DEGMMA) or P(PEGMMA-co-DEGMMA, $1: 9$ and $1: 5)$. Experiments were performed by increasing either salt concentration or temperature in a stepwise manner. $\mathrm{NaClO}_{4}, \mathrm{NaCl}$ and $\mathrm{Na}_{2} \mathrm{SO}_{4}$ salts were investigated, due to their ability to raise or lower the cloud point temperature of polymers, according to the Hofmeister series (Fig. S4, ESI $\dagger$ ). ${ }^{29}$

Introducing an increased concentration of a salt solution in the chamber over a bare QCM-D crystal leads to a decrease in the quartz crystal frequency and an increase of the dissipation referred to as the bulk shift. The response due to brush collapse or swelling discussed below will therefore always be a combined signal of this bulk shift and the brush response. Fig. 3a shows an example of the change in dissipation with increasing $\mathrm{Na}_{2} \mathrm{SO}_{4}$ concentration. The crystal with ungrafted PBrEDOT shows a consistent increase in dissipation in line with the expected bulk shift, whereas the grafted PBrEDOT films show a more complex result. PBrEDOT- $g$-PDEGMMA also shows increased dissipation, but to a lesser extent than the ungrafted sample, while the two P(PEGMMA-co-DEGMMA) copolymers decrease in dissipation for the lower salt concentrations. A corresponding increase in the frequency response is also seen (Fig. S7, ESI $†$ ). These results correspond to a decrease in mass (dehydration) and stiffening of the brush layer. It is important to note that brush collapse can occur while the brushes are only partially dehydrated, ${ }^{37}$ meaning that the observed transition point can differ depending on whether the frequency or dissipation is analyzed. In this study, cloud points of the brushes were calculated from the dissipation data (5th overtone, $25 \mathrm{MHz}$ ), as it provides a more direct indication of brush conformation.

To look at the data in a clearer manner, the response for the grafted films has been normalized by the response seen for the ungrafted film (relating to bulk shifts) and plotted against temperature (Fig. 3b) or salt concentration (Fig. 3c and d). More data is available in the ESI: $\dagger$ Fig. S8 gives corresponding frequency responses for changes in temperature (including frequency and dissipation data in $\mathrm{NaCl}$ ), while Fig. S9 (ESI $\dagger$ ) shows the frequency responses for increasing salt concentration. Repeat measurements with salt concentrations are also given in the ESI $\dagger$ (Fig. S10).

The QCM-D data clearly demonstrates the dehydration of the grafted brushes in $\mathrm{Na}_{2} \mathrm{SO}_{4}$ and the swelling of the brushes in the $\mathrm{NaClO}_{4}$ solutions. The deviation from the trend at higher $\mathrm{NaClO}_{4}$ concentrations is attributable, in part, to the diminishing 'salting in' effect of perchlorate with increased concentration. ${ }^{38}$ The changes in gradient in Fig. $3 \mathrm{~b}-\mathrm{d}$ are interpreted as relating to the critical temperature or salt concentration where the rate of dehydration changes, and it is seen that this point varies with the brush composition. In terms of temperature (Fig. 3b), very little collapse is seen for PBrEDOT- $g$-PDEGMMA, indicating that these 

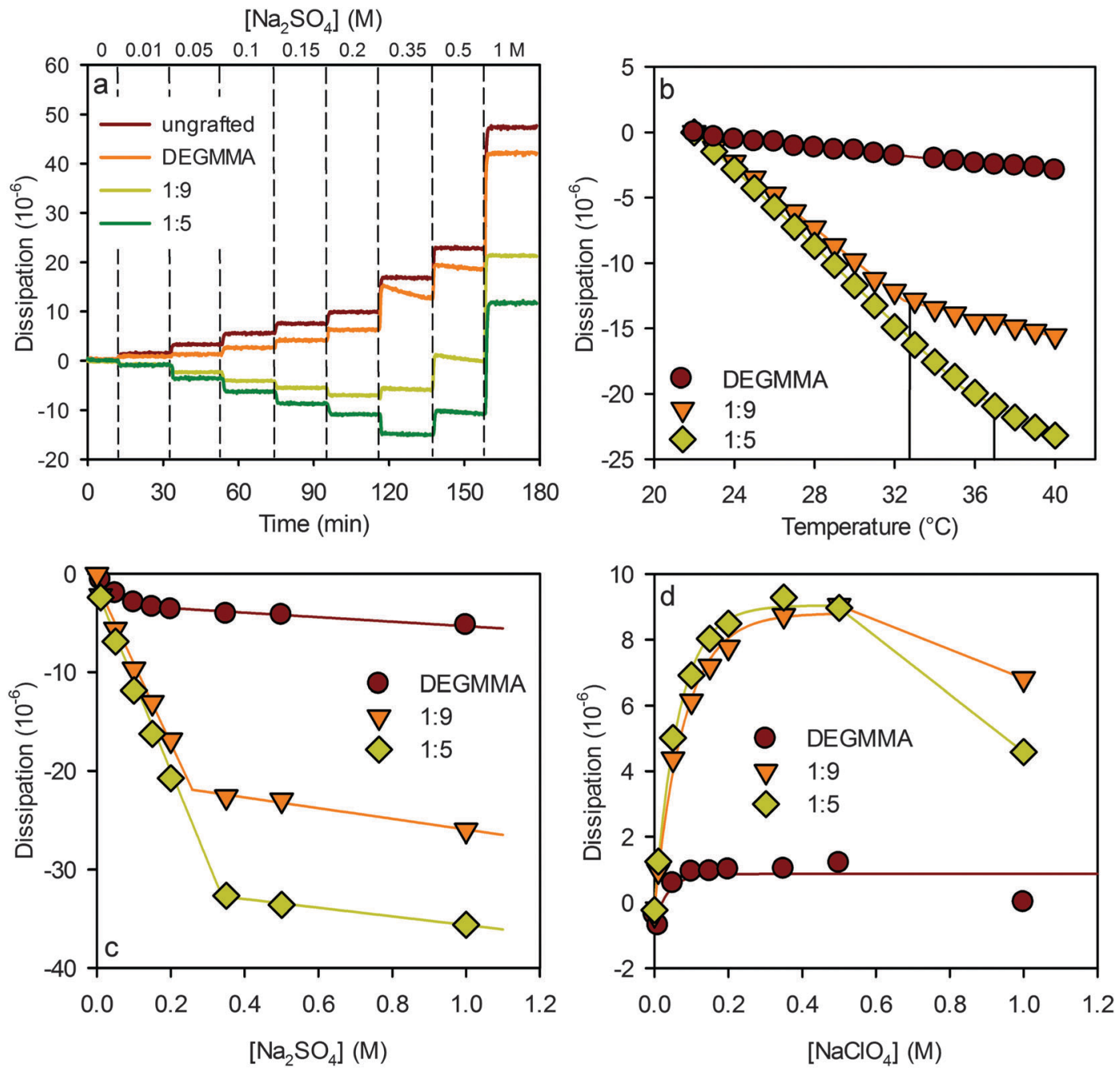

Fig. 3 (a) Dissipation (5th overtone) of (top to bottom) ungrafted PBrEDOT, and PBrEDOT grafted with PDEGMMA and P(PEGMMA-CO-DEGMMA, 1: 9 and 1:5) as $\mathrm{Na}_{2} \mathrm{SO}_{4}$ concentration increases from $10 \mathrm{mM}$ to $1 \mathrm{M}$. (b) Dissipation of PDEGMMA, P(PEGMMA-CO-DEGMMA, 1:9 and 1:5) brushes (normalized on ungrafted sample) in $0.1 \mathrm{M} \mathrm{Na}_{2} \mathrm{SO}_{4}$ as temperature increases from $22-40{ }^{\circ} \mathrm{C}$. (c and d) Normalized dissipation of PDEGMMA and P(PEGMMA-CO-DEGMMA, 1:9 and 1:5) brushes in increasing $\mathrm{Na}_{2} \mathrm{SO}_{4}$ and $\mathrm{NaClO}_{4}$ solutions respectively at $22^{\circ} \mathrm{C}$.

brushes were already collapsed at the starting temperature $\left(22^{\circ} \mathrm{C}\right.$, $0.1 \mathrm{M} \mathrm{Na}_{2} \mathrm{SO}_{4}$ ), as might be expected from the turbidity measurements in solution (cloud point $\sim 23{ }^{\circ} \mathrm{C}$, see Fig. S4a, ESI $\dagger$ ). Both of the PBrEDOT- $g$-P(PEGMMA-co-DEGMMA) compositions investigated show linear brush collapse, which tails off at about $32{ }^{\circ} \mathrm{C}$ for the $1: 9$ composition and $36{ }^{\circ} \mathrm{C}$ for the $1: 5$ composition. At $22{ }^{\circ} \mathrm{C}$, the critical concentration of sulfate is determined as around $0.1 \mathrm{M}$ for PDEGMMA brushes and $0.25 \mathrm{M}$ and $0.35 \mathrm{M}$ for the $1: 9$ and 1:5 compositions respectively. However, due to the observed broadening of the cloud point transition for brushes grafted from these surfaces, it is unclear whether this corresponds to complete collapse of the brushes, or if further brush collapse has been hindered by the presence of trapped water molecules. ${ }^{37}$

\subsection{Electrochemical studies of PBrEDOT-g-P(PEGMMA-co- DEGMMA, 1 : 5)}

With the salt responsiveness of the brushes confirmed, attention turned to investigating the electrochemical properties of the PBrEDOT- $g$-P(PEGMMA-co-DEGMMA, 1:5) films by both cyclic voltammetry (CV) and electrical impedance spectroscopy (EIS).

Cyclic voltammograms of ungrafted PBrEDOT and PBrEDOT- $g$ P(PEGMMA-co-DEGMMA, 1:5) in $0.1 \mathrm{M} \mathrm{NaClO}_{4}$ or $\mathrm{Na}_{2} \mathrm{SO}_{4}$ at $30{ }^{\circ} \mathrm{C}$ are given in Fig. 4. These CVs demonstrate that the grafted films retain their electroactivity, despite the presence of 'insulating' brushes on the surface of the CP film. Moreover, in $\mathrm{NaClO}_{4}$, the grafted film shows a greater current response than the ungrafted film (Fig. 4a). This may be attributed to the increased solvation of PBrEDOT caused by swollen grafted brushes that may interpenetrate the CP layer, as discussed above, as well as an increase in capacitance due to the brush layer. Grafting also significantly shifts the redox peaks towards lower potentials (the oxidation peaks shift from $+0.43 \mathrm{~V}$ and $+0.60 \mathrm{~V}$ to $+0.28 \mathrm{~V}$, and from $+0.38 \mathrm{~V}$ to $+0.08 \mathrm{~V}$ for reduction), indicating that the grafted films are more easily oxidized and reduced. Oxidation and reduction waves are also appreciably more uniform after grafting, displaying one oxidation/reduction peak instead of 

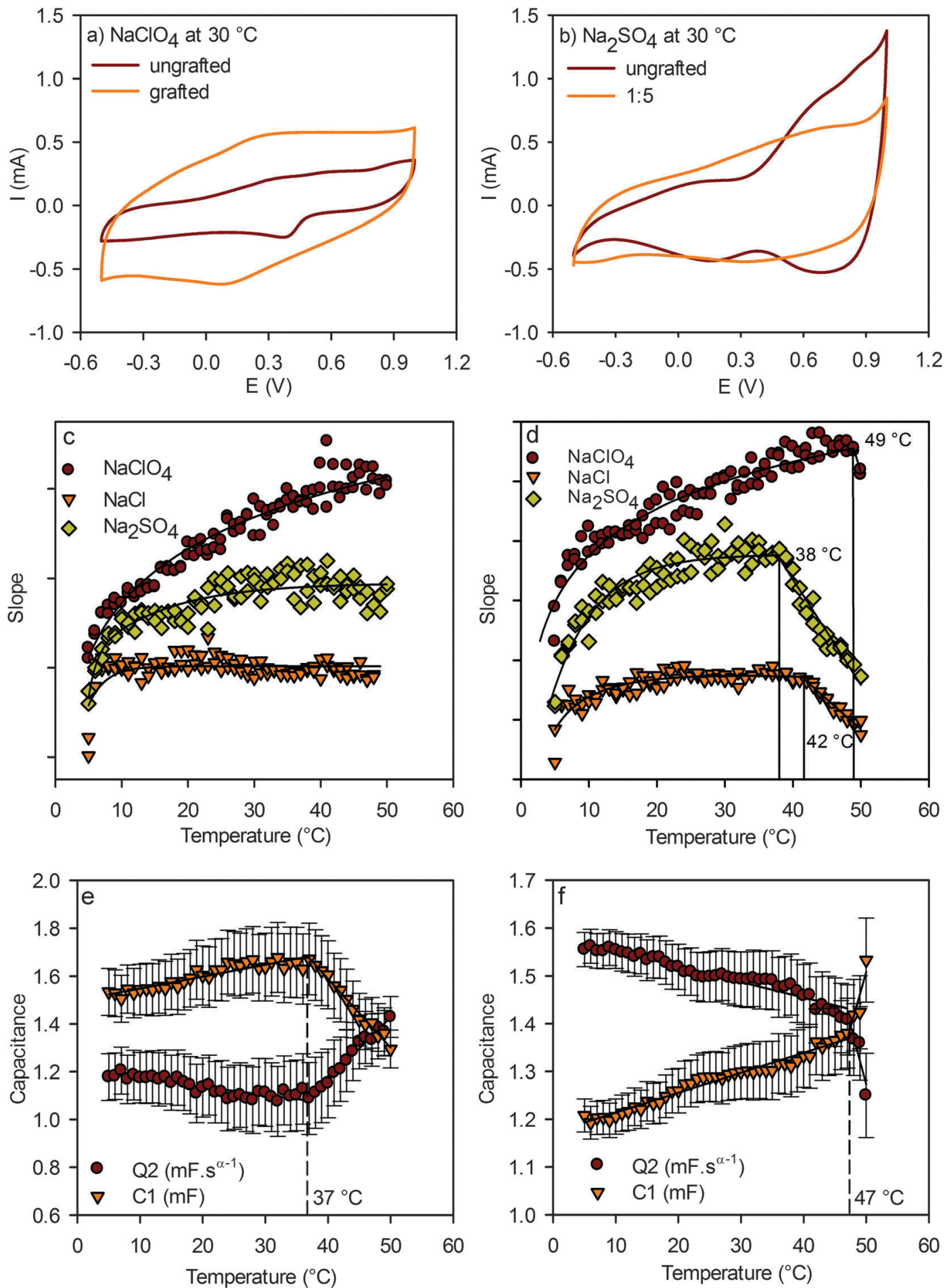

Fig. 4 Cyclic voltammograms of ungrafted PBrEDOT and grafted PBrEDOT-g-P(PEGMMA-CO-DEGMMA, $1: 5)$ at $30{ }^{\circ} \mathrm{C}$, in (a) $0.1 \mathrm{M} \mathrm{NaClO} 4$ and (b) $0.1 \mathrm{M}$ $\mathrm{Na}_{2} \mathrm{SO}_{4}$. Current response was normalized by surface area. Low frequency $(<1 \mathrm{~Hz})$ gradients of Nyquist plots of ungrafted PBrEDOT (c) and PBrEDOT- $g$ P(PEGMMA-CO-DEGMMA, 1:5) (d) as a function of increasing temperature in $0.1 \mathrm{M} \mathrm{Na}_{2} \mathrm{SO}_{4}, 0.1 \mathrm{M} \mathrm{NaCl}$ and $0.1 \mathrm{M} \mathrm{NaClO}_{4}$ (all data offset). (e and f) Fitted capacitance values as a function of temperature for PBrEDOT-g-P(PEGMMA-co-DEGMMA) in $0.1 \mathrm{M} \mathrm{Na}_{2} \mathrm{SO}_{4}$ and $0.1 \mathrm{M} \mathrm{NaClO}_{4}$ respectively.

multiple redox peaks seen before grafting. CVs recorded in $0.1 \mathrm{M} \mathrm{Na}_{2} \mathrm{SO}_{4}$ (Fig. 4b) are more difficult to interpret, as the brushes may start to be partially dehydrated at this temperature. There is an increase in capacitive currents seen at potentials below $+0.50 \mathrm{~V}$, and the oxidation peak at $+0.75 \mathrm{~V}$ in the ungrafted film appears to have broadened and shifted slightly to $+0.70 \mathrm{~V}$ in the grafted CV.

CVs recorded in both salts at $5{ }^{\circ} \mathrm{C}$ and $50{ }^{\circ} \mathrm{C}$ are also available in the ESI $\dagger$ (Fig. S11). In $\mathrm{NaClO}_{4}$, the capacitive effect of the brush layer diminishes as the temperature increases 
(Fig. S11a and b, ESI $\dagger$ ). At $50{ }^{\circ} \mathrm{C}$, when the brushes are expected to be collapsed, there is little difference between the grafted and ungrafted CVs. In $\mathrm{Na}_{2} \mathrm{SO}_{4}$ (Fig. S11c and d, ESI $\dagger$ ), the capacitance of the brushes is also less pronounced at both temperatures possibly due to partial brush dehydration beginning even at $5{ }^{\circ} \mathrm{C}$.

Electrochemical impedance spectroscopy (EIS) is well suited to probe the change in electrochemical properties of the interface, due to changes in brush conformation. In order to specifically probe the interfacial layer, non-faradaic impedance was measured for ungrafted and grafted samples at temperatures from 5 to $50{ }^{\circ} \mathrm{C}$ (Fig. S12, ESI $\dagger$ ). As expected, the traces shift to lower $Z^{\prime}$ values with increasing temperature, as the solution resistance (and to a lesser extent the film charge transfer resistance) decreases due to increased ion mobility.

Fig. $4 \mathrm{c}$ and $\mathrm{d}$ show the values of the slopes of the impedance diagram of the ungrafted PBrEDOT and grafted P(PEGMMA- $c o$ DEGMMA, 1:5) samples at low frequencies $(<1 \mathrm{~Hz})$. The measurements made on the grafted sample show a sudden trend change at a temperature corresponding to the expected transition temperature of the brush, which is not present in the ungrafted control. To further investigate this, the data was also modelled using a simplified Bisquert model for a transmission line. In this model, both solution resistance and film resistance were shown to decrease with increasing temperature (Fig. S13a and b, ESI $\dagger$ ). However, the alpha values demonstrate the same trends as the low frequency slopes, increasing with temperature followed by a decrease at the transition temperature (Fig. S13c, ESI $\dagger$ ). We attribute this to an increase in local surface roughness, which increases the 'leakiness' of the capacitor. The extracted capacitance values also show a clear trend change at the temperature corresponding to brush collapse, and in Fig. 4e and $\mathrm{f}$ it can be seen how these conductive polymer tethered brushes collapse at a higher temperature in perchlorate as compared to sulfate electrolyte. The derived transition temperatures are in good agreement with cloud point studies recorded in solution (Fig. S4, ESI $\dagger$ ) and the QCM-D data discussed above (Fig. 3), as well as with expectations based on the literature. ${ }^{30,39}$

\subsection{Summary of switching behavior}

Table 2 summarizes switching behavior of the P(PEGMMA-coDEGMMA, 1:5) brushes grafted from PBrEDOT films obtained by using multiple techniques discussed above, and compares these values to the transition temperature of corresponding free polymers recorded in solution.

\subsection{Antifouling behavior}

To further demonstrate the antifouling behavior of these grafted layers, samples were exposed to $20 \%$ serum for 1 hour,

Table 2 Observed switching behavior of P(PEGMMA-co-DEGMMA, 1:5)

\begin{tabular}{lllll} 
& $\begin{array}{l}\text { Transition } \\
\text { temperature } \\
\text { (solution) }\left({ }^{\circ} \mathrm{C}\right)\end{array}$ & $\begin{array}{l}\text { Transition } \\
\text { temperature } \\
(\text { QCM-D })\left({ }^{\circ} \mathrm{C}\right)\end{array}$ & $\begin{array}{l}\text { Transition } \\
\text { temperature } \\
(\text { EIS })\left({ }^{\circ} \mathrm{C}\right)\end{array}$ & $\begin{array}{l}\text { Salt-induced } \\
\text { switch }\end{array}$ \\
\hline $\mathrm{NaClO}_{4}$ & 53 & - & 49 & No \\
$\mathrm{NaCl}$ & 45 & - & 42 & Yes \\
$\mathrm{Na}_{2} \mathrm{SO}_{4}$ & 40 & 36 & 38 & Yes
\end{tabular}

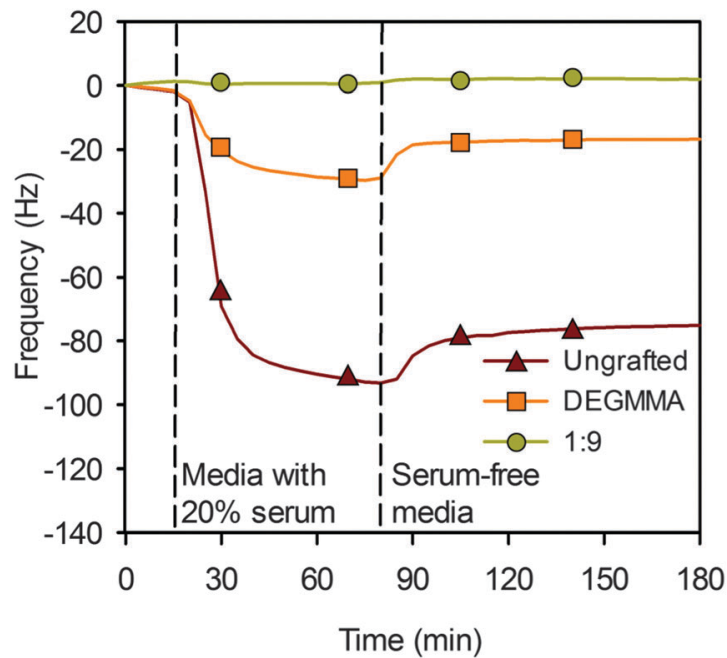

Fig. 5 Frequency response of ungrafted PBrEDOT, and PBrEDOT grafted with PDEGMMA and P(PEGMMA-CO-DEGMMA, 1:9 and 1:5) brushes in serum-free media and $20 \%$ serum, measured using $Q C M-D$.

and monitored in real-time by QCM-D. The ungrafted PBrEDOT and the PBrEDOT- $g$-PDEGMMA samples showed a significant decrease in the frequency with the addition of serum (Fig. 5), due to protein adsorption. The PDEGMMA brushes are expected to be collapsed under these conditions, and therefore are not expected to be as protein rejecting as swollen brushes. However, there was a marked reduction of protein adsorption compared to the ungrafted material. Assuming the Sauerbrey equation applies (confirmed by negligible dissipation and overlapping overtones), ${ }^{40}$ the amount of adsorbed protein is calculated to be $1382 \mathrm{ng} \mathrm{cm}^{-2}$

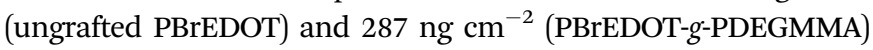
after washing in serum-free media. In contrast, the PBrEDOT- $g$ P(PEGMMA-co-DEGMMA, 1:9) sample showed little change in frequency, decreasing by only $0.6 \mathrm{~Hz}$ upon addition of protein, suggesting little change in mass and therefore negligible protein adsorption. Corresponding dissipation data can be viewed in the ESI $\dagger$ (Fig. S14).

It is important to note that the samples exposed to serum had already been used for several swelling/collapse cycles (salt and temperature) as well as cyclic voltammetry measurements, and remain protein rejecting regardless. This procedure for modifying conductive polymer materials therefore offers a very stable and reliable surface modification with good protein rejecting properties.

\section{Conclusion}

This work demonstrates the fabrication of conducting polymer films grafted with salt- and temperature-responsive polymer brushes based on P(DEGMMA-co-PEGMMA) grafted from PBrEDOT. The films were carefully characterized by ellipsometry, AFM, QCM-D, cyclic voltammetry and EIS. Cyclic voltammetry measurements clearly established that the grafted PBrEDOT films were electroactive, and that their electrochemical behavior could be modulated by temperature and the type of salt present. 
In fact, the electroactivity of PBrEDOT was enhanced in $0.1 \mathrm{M}$ $\mathrm{NaClO}_{4}$ at lower temperatures $\left(\leq 30{ }^{\circ} \mathrm{C}\right)$, due to solvating effect of the brushes. QCM-D and EIS techniques were used to investigate the switching behavior of the grafted brushes. The transition temperatures estimated from these methods were all in good agreement, showing salt-dependent transition temperatures following the Hofmeister series of anions. The composition of the brushes could be conveniently tailored to change the transition temperature of the system.

We have shown that these modified conductive polymer films provide tailored protein resistance even after repeated brush collapse/swelling cycles and electrochemistry. Therefore, this study forms a basis for applications of these materials such as electrically addressable biomaterial interfaces, microfluidic devices and chromatographic substrates.

\section{Conflict of interest}

The authors declare no competing financial interest.

\section{Acknowledgements}

The authors would like to thank the MacDiarmid Institute for Advanced Materials and Nanotechnology for funding this research. They also thank the Australian Research Council for financial support though the Australian Research Fellowship of Assoc. Prof. Michael Higgins and Laureate Fellowship of Prof Gordon Wallace (FL110100196), as well as support through the Australian Centre of Excellence for Electromaterials Science (CE140100012). We also acknowledge the Australian National Fabrication Facility (ANFF) for access to equipment.

\section{References}

1 M. A. C. Stuart, W. T. S. Huck, J. Genzer, M. Muller, C. Ober, M. Stamm, G. B. Sukhorukov, I. Szleifer, V. V. Tsukruk, M. Urban, F. Winnik, S. Zauscher, I. Luzinov and S. Minko, Nat. Mater., 2010, 9, 101-113.

2 S. H. Anastasiadis, Langmuir, 2013, 29, 9277-9290.

3 M. Krishnamoorthy, S. Hakobyan, M. Ramstedt and J. E. Gautrot, Chem. Rev., 2014, 114, 10976-11026.

4 Y. Stetsyshyn, K. Fornal, J. Raczkowska, J. Zemla, A. Kostruba, H. Ohar, M. Ohar, V. Donchak, K. Harhay, K. Awsiuk, J. Rysz, A. Bernasik and A. Budkowski, J. Colloid Interface Sci., 2013, 411, 247-256.

5 M. F. Delcroix, G. L. Huet, T. Conard, S. DemoustierChampagne, F. E. Du Prez, J. Landoulsi and C. C. DupontGillain, Biomacromolecules, 2012, 14, 215-225.

6 Y. K. Jhon, R. R. Bhat, C. Jeong, O. J. Rojas, I. Szleifer and J. Genzer, Macromol. Rapid Commun., 2006, 27, 697-701.

7 G. Wallace and G. Spinks, Soft Matter, 2007, 3, 665-671.

8 B. J. Schwartz, Annu. Rev. Phys. Chem., 2003, 54, 141-172.

9 J. A. Irvin and K. Winkel, Functional Polymer Films, WileyVCH Verlag GmbH \& Co. KGaA, Weinheim, Germany, 2011, ch. 32 , pp. 983-1015, DOI: 10.1002/9783527638482.
10 R. Ravichandran, S. Sundarrajan, J. R. Venugopal, S. Mukherjee and S. Ramakrishna, J. R. Soc., Interface, 2010, 7, S559-S579.

11 M. J. Higgins, P. J. Molino, Z. Yue and G. G. Wallace, Chem. Mater., 2012, 24, 828-839.

12 G. G. Wallace, S. E. Moulton and G. M. Clark, Science, 2009, 324, 185-186.

13 K. Svennersten, K. C. Larsson, M. Berggren and A. RichterDahlfors, Biochim. Biophys. Acta, Gen. Subj., 2011, 1810, 276-285.

14 G. Kaur, R. Adhikari, P. Cass, M. Bown and P. Gunatillake, RSC Adv., 2015, 5, 37553-37567.

15 P. Petrov, P. Mokreva, C. Tsvetanov and L. Terlemezyan, Colloid Polym. Sci., 2008, 286, 691-697.

16 Y. Wang, A. J. Zappas, J. N. Wilson, I.-B. Kim, K. M. Solntsev, L. M. Tolbert and U. H. F. Bunz, Macromolecules, 2008, 41, 1112-1117.

17 C. D. Grande, M. C. Tria, G. Jiang, R. Ponnapati and R. Advincula, Macromolecules, 2011, 44, 966-975.

18 A.-D. Bendrea, G. Fabregat, J. Torras, S. Maione, L. Cianga, L. J. del Valle, I. Cianga and C. Aleman, J. Mater. Chem. B, 2013, 1, 4135-4145.

19 M. E. Welch, T. Doublet, C. Bernard, G. G. Malliaras and C. K. Ober, J. Polym. Sci., Part A: Polym. Chem., 2015, 53, 372-377.

20 H. Zhao, B. Zhu, S.-C. Luo, H.-A. Lin, A. Nakao, Y. Yamashita and H.-h. Yu, ACS Appl. Mater. Interfaces, 2013, 5, 4536-4543.

21 J. Malmström, M. K. Nieuwoudt, L. T. Strover, A. Hackett, O. Laita, M. A. Brimble, D. E. Williams and J. Travas-Sejdic, Macromolecules, 2013, 46, 4955-4965.

22 L. Strover, C. Roux, J. Malmström, Y. Pei, D. E. Williams and J. Travas-Sejdic, Synth. Met., 2012, 162, 381-390.

23 Y. Pei, J. Travas-Sejdic and D. E. Williams, Langmuir, 2012, 28, 8072-8083.

24 Y. Pei, J. Travas-Sejdic and D. E. Williams, Langmuir, 2012, 28, 13241-13248.

25 E. Wischerhoff, K. Uhlig, A. Lankenau, H. G. Börner, A. Laschewsky, C. Duschl and J.-F. Lutz, Angew. Chem., Int. Ed., 2008, 47, 5666-5668.

26 O. H. Kwon, A. Kikuchi, M. Yamato, Y. Sakurai and T. Okano, J. Biomed. Mater. Res., 2000, 50, 82-89.

27 M. A. Cole, N. H. Voelcker, H. Thissen and H. J. Griesser, Biomaterials, 2009, 30, 1827-1850.

28 M. Luzon, C. Boyer, C. Peinado, T. Corrales, M. Whittaker, L. Tao and T. P. Davis, J. Polym. Sci., Part A: Polym. Chem., 2010, 48, 2783-2792.

29 J. P. Magnusson, A. Khan, G. Pasparakis, A. O. Saeed, W. Wang and C. Alexander, J. Am. Chem. Soc., 2008, 130, 10852-10853.

30 C. R. Becer, S. Hahn, M. W. M. Fijten, H. M. L. Thijs, R. Hoogenboom and U. S. Schubert, J. Polym. Sci., Part A: Polym. Chem., 2008, 46, 7138-7147.

31 J.-F. Lutz and A. Hoth, Macromolecules, 2006, 39, 893-896.

32 A. A. Brown, N. S. Khan, L. Steinbock and W. T. S. Huck, Eur. Polym. J., 2005, 41, 1757-1765. 
33 L. Srisombat, A. C. Jamison and T. R. Lee, Colloids Surf., A, 2011, 390, 1-19.

34 J. K. Oh, K. Min and K. Matyjaszewski, Macromolecules, 2006, 39, 3161-3167.

35 X. Laloyaux, B. Mathy, B. Nysten and A. M. Jonas, Langmuir, 2010, 26, 838-847.

36 E. Poverenov, M. Li, A. Bitler and M. Bendikov, Chem. Mater., 2010, 22, 4019-4025.
37 G. Zhang and C. Wu, Macromol. Rapid Commun., 2009, 30, 328-335.

38 Y. Zhang, S. Furyk, L. B. Sagle, Y. Cho, D. E. Bergbreiter and P. S. Cremer, J. Phys. Chem. C, 2007, 111, 8916-8924.

39 E. Svetushkina, N. Puretskiy, L. Ionov, M. Stamm and A. Synytska, Soft Matter, 2011, 7, 5691-5696.

40 G. Sauerbrey, Z. Phys., 1959, 155, 206-222. 